\title{
Predictors of atrial fibrillation recurrence after cryoballoon ablation
}

This article was published in the following Dove Press journal:

Journal of Blood Medicine

29 June 2015

Number of times this article has been viewed

\author{
Tolga Aksu' \\ Erkan Baysal ${ }^{2}$ \\ Tümer Erdem Guler' \\ Sukriye Ebru Golcuk ${ }^{3}$ \\ İsmail Erden' \\ Kazim Serhan Ozcan' \\ 'Department of Cardiology, Derince \\ Education and Research Hospital, \\ Kocaeli, ${ }^{2}$ Department of Cardiology, \\ Diyarbakir Education and Research \\ Hospital, Diyarbakir, ${ }^{3}$ Department of \\ Cardiology, Faculty of Medicine, Koc \\ University, Istanbul, Turkey
}

Objective: Cryoballoon ablation (CA) is a safe and efficient method for pulmonary vein isolation in the treatment of paroxysmal atrial fibrillation (AF). There are conflicting results about the predictors of AF recurrence. The aim of this study is to evaluate the role of hematological indices to predict $\mathrm{AF}$ recurrence after $\mathrm{CA}$.

Methods: A total of 49 patients (mean age $58.3 \pm 12.2$ years, $51.02 \%$ female) with symptomatic paroxysmal AF underwent CA procedure. One hundred and sixty-eight pulmonary veins were used for pulmonary vein isolation with the second-generation cryoballoon. The hematological samples were obtained before and 24 hours after ablation.

Results: At a mean follow-up of 10.2 \pm 2.4 months, the probability of being arrhythmia-free after a single procedure was $86 \%$. Patients with AF recurrence had higher red cell distribution width levels $(16.10 \% \pm 1.44 \%$ vs $14.87 \% \pm 0.48 \%, P=0.035)$. The neutrophil/lymphocyte ratio, erythrocyte sedimentation rate, and C-reactive protein levels were detected in the patients with or without recurrence. Left atrial diameter $(46.28 \pm 4.30 \mathrm{~mm}$ vs $41.02 \pm 4.10 \mathrm{~mm}, P=0.002)$, duration of $\mathrm{AF}(6.71 \pm 4.57$ years vs $3.59 \pm 1.72$ years, $P=0.003)$, and age $(65.01 \pm 15.39$ years vs $54.29 \pm 11.32$ years, $P=0.033$ ) were the other independent predictors of clinical recurrence after CA. Multiple regression analysis revealed that left atrial diameter was the only independent predictor for $\mathrm{AF}$ recurrence $(P=0.012)$.

Conclusion: In this study of patients with paroxysmal AF undergoing cryoablation, increased preablation red cell distribution width levels, and not C-reactive protein or erythrocyte sedimentation rate, was associated with a higher rate of AF recurrence. Our results support the role of a preablation, proinflammatory, and pro-oxidant environment in the development of AF recurrence after ablation therapy but suggest that other factors are also important.

Keywords: ablation, atrial fibrillation, cryoballoon, neutrophil, CRP, oxidative stress

\section{Introduction}

Atrial fibrillation (AF) is the most common cardiac arrhythmia, with an estimated prevalence of $1 \%-3 \% .^{1,2}$ Catheter ablation of $\mathrm{AF}$ is recommended for patients with drug refractory symptomatic paroxysmal $\mathrm{AF}^{3}$ Pulmonary vein isolation (PVI) still remains the cornerstone of AF ablation procedures. ${ }^{3}$ Currently, various underlying pathophysiological mechanisms such as inflammation and oxidative stress have been thought to be associated with AF.

Red cell distribution width (RDW), a measurement of the variability and size of erythrocytes, can be easily measured during routine complete blood count. A relationship between RDW and various cardiovascular diseases and AF has been found in recent studies. ${ }^{4-6}$
Correspondence: Tolga Aksu

Department of Cardiology, Derince

Education and Research Hospital,

Ibni-sina Street, No 4,

Derince, Kocaeli 41000, Turkey

Tel +905319903278

Fax +902623178000

Email aksutolga@gmail.com 
The neutrophil/lymphocyte ratio (NLR), which can be derived from the white blood cell count, is a novel marker of systemic inflammation. The elevation of NLR has been shown to indicate poor prognosis of many cardiovascular diseases $^{7-10}$ and AF. ${ }^{11}$ C-reactive protein (CRP) and erythrocyte sedimentation rate (ESR) are acute-phase reactants whose levels increase as a response to proinflammatory cytokines and other endogenous signals of innate immunity or tissue damage. Several studies evaluating the accuracy of high-sensitive CRP (hs-CRP) in predicting AF recurrence after cardioversion or catheter ablation have been published. ${ }^{12-22}$

The aim of this study is to evaluate the role of hematological indices to predict AF recurrence after cryoballoon ablation (CA).

\section{Methods}

\section{Patients}

The study population consisted of 49 consecutive patients who underwent PVI with cryoballoon technique for 12-lead verified, symptomatic, and drug refractory paroxysmal AF. Patients whose episodes of AF have been self-terminated within 7 days were defined as paroxysmal AF. The indication for ablation was based on the guidelines. ${ }^{3}$ Detailed inclusion and exclusion criteria for patients are outlined in Table 1.

Table I Study inclusion and exclusion criteria

\begin{tabular}{l} 
Inclusion criteria \\
Patients age I 8 or greater \\
Paroxysmal AF (AF that terminates spontaneously or with \\
intervention within 7 days of onset) \\
Symptomatic and drug refractory (at least one anti arrhythmic) AF \\
At least three episodes of AF must have been documented by ECG or \\
Holter before the procedure \\
Patients must be on continuous anticoagulation with warfarin \\
(INR $2-3$ ) for $>4$ weeks prior to the ablation \\
Patients must be able and willing to provide written informed consent \\
to the procedure \\
Exclusion criteria \\
History of acute or chronic infective disease \\
History of either acute or inflammatory disease \\
Thyroid dysfunction \\
Chronic kidney disease \\
Persistent or permanent AF \\
Inadequate anticoagulation as defined in the inclusion criteria \\
Left atrial thrombus on transesophageal echo prior to the procedure \\
Contraindications to any anticoagulant \\
Previous AF ablation procedure \\
Left atrial size $>55$ mm \\
Left ventricular ejection fraction $<30 \%$ \\
Congestive heart failure with New York Heart Association class IV \\
\hline
\end{tabular}

Abbreviations: AF, atrial fibrillation; ECG, electrocardiogram; INR, international normalized ratio.
Symptomatic severity of the patients was recorded according to the European Heart Rhythm Association score. $\mathrm{CHA}_{2} \mathrm{DS}_{2}$-VASc scores were calculated for each patient based on the relevant guidelines..$^{23}$ Written informed consent was obtained from all patients before the procedure. Kocaeli University Ethical Committee approved the study.

\section{Preprocedural evaluation}

Standard transthoracic echocardiography was performed in all patients to evaluate left atrium (LA) diameters and to rule out structural abnormality. In all patients, LA thrombus was ruled out by transesophageal echocardiography prior to the procedure. Patients were all anticoagulated with warfarin to maintain an international normalized ratio of 2-3 for at least 4 weeks prior the procedure. Warfarin was interrupted before the procedure. The procedures were done if international normalized ratio value was $<1.5$. Antiarrhythmic drugs were discontinued five half-lives before the procedure.

\section{Blood samples}

Blood samples for the complete blood count analysis were collected on admission and 1 day after catheter ablation. Measurements of hematologic parameters were performed on an automatic blood counter (A Sysmex XE-2100; Symex, Kobe, Japan). The NLR was computed using the absolute neutrophil count divided by the absolute lymphocyte count. The level of CRP in serum was determined with the latex agglutination methods. The normal CRP value was $<0.3 \mathrm{mg} / \mathrm{dL}$. ESR is a manual test in which the level of blood collected in a Western sedimentation rate tube is read by a technologist after a specific time period. Normal ESR range is $<20 \mathrm{mg} / \mathrm{dL}$.

\section{Ablation procedure}

The procedures were performed under local anesthesia. Transseptal punctures were performed under fluoroscopic guidance only. After transseptal puncture, intravenous heparin was used to maintain an activated clotting time of 300-400 seconds. A single or double transseptal puncture was performed using a conventional circumferential mapping catheter (Inquiry ${ }^{\mathrm{TM}}$, Optima ${ }^{\mathrm{TM}}$; St Jude Medical, Sylmar, CA, USA) or the customized mapping catheter (Achieve ${ }^{\mathrm{TM}}$; Medtronic, Minneapolis, MN, USA). Positioning of the 28-mm cryoballoon catheter (Arctic Front Advance ${ }^{\mathrm{TM}}$; Medtronic) was achieved using the guide wire and the 12 Fr-steerable sheath (Flexcath, Medtronic). While delivering cryoenergy to right pulmonary veins, a $6 \mathrm{~F}$ decapolar coronary sinus catheter or a quadripolar diagnostic catheter 
were positioned in the superior vena cava for phrenic nerve stimulation.

Before each freeze, grade of occlusion (semiquantitative scale from 1 - poor occlusion to 4 - perfect occlusion) was quantified with an injection of contrast medium. ${ }^{24}$ After confirmation of pulmonary vein occlusion by contrast injection, the 240-second freezing cycle was initiated. After two freezing cycles, PVI was assessed by circumferential mapping catheter. If PVI was not achieved within five attempts, the customized mapping catheter was exchanged for a stiffer wire (Amplatz Ultra Stiff, COOK Medical Inc., IN, USA). Isolation of pulmonary veins was defined as the presence of both entrance and exit blocks.

\section{Postprocedural evaluation}

A transthoracic echocardiography was performed immediately after the procedure to exclude the presence of pericardial effusion. All patients were followed up for at least 12 hours in the intensive care unit. Patients were then discharged provided that their clinical statuses were stable. Oral anticoagulation was initiated in the evening on the day of ablation unless pericardial effusion was detected and continued for at least 3 months after the procedure. Antiarrhythmic drug treatment was also continued for at least 3 months.

\section{Follow-up}

Regular follow-up consisted of outpatient clinic visits at 1 months, 3 months, and 6 months after the procedure and included a detailed history for arrhythmia-related symptoms (palpitations, chest discomfort, fatigue, and dizziness), physical examination, 12-lead electrocardiogram (ECG), and 24-hour Holter monitoring.

The need for further oral anticoagulation was evaluated on the third month based on the $\mathrm{CHA}_{2} \mathrm{DS}_{2}$-VASc score. Outcome was measured as per the guidelines in the recent consensus document. Any episode of AF, atrial flutter, or atrial tachycardia lasting for at least 30 seconds was defined as recurrence. ${ }^{6}$ A blanking period was not considered for the study. Any recurrence occurring in the first 3 months was classified as an early recurrence, whereas recurrence after this period was considered as late recurrence. Only patients with at least 6 months of follow-up were included in the study.

The patients with late AF recurrence underwent redoprocedure to evaluate cause of recurrence following similar preparatory steps as during the index procedure. A diagnostic catheter was used to evaluate the status of isolation or reconnection per vein.
None of the patients had clinical signs of coronary ischemic episodes either prior to or at the end of the procedure. There were no changes of the ST-segment when comparing ECG tracings before, during, or after the procedure.

\section{Statistical analysis}

SPSS 17.0 software (IBM Corporation, Armonk, NY, USA) was used for statistical analysis. All the quantitative variables with a normal distribution were reported as mean \pm standard deviation and compared using the Student's $t$-test. For values with nonnormal distribution, comparison was performed with Mann-Whitney $U$-test. For the descriptive variables comparison, the Pearson $\chi^{2}$ test or Fisher's exact tests were used, when appropriate. The independent association of clinical variables with recurrence was assessed utilizing multiple linear regression analysis. A Kaplan-Meier analysis was used to analyze the recurrent atrial tachycardia-free survival after cryoablation. $P$-value $<0.05$ was considered statistically significant.

\section{Results \\ Patient characteristics}

We analyzed 49 patients (25 males) with mean age of $54.6 \pm 10.7$ years and LA diameter size of $41.77 \pm 4.49 \mathrm{~cm}$; Ejection fraction of 58.57 \pm 5.01 ; unsuccessful antiarrhythmic drug number of 1.41 \pm 0.6 ; and median European Heart Rhythm Association score of 2. Baseline characteristics and demographical features of the patients are presented in Table 2. After a mean follow-up period of 10.2 \pm 2.4 months (range 8-12), early recurrence was observed in $5(10.2 \%)$ patients and late recurrence was observed in $2(4.08 \%)$ patients (Figure 1$)$. The patients with AF recurrence (Group 1) were significantly older

Table 2 Baseline clinical and echocardiographic characteristics of the study population $(n=49)$

\begin{tabular}{ll}
\hline Age, years (mean $\pm \mathrm{SD})$ & $55.8 \pm 12.4$ \\
Sex, male; $\mathrm{n}(\%)$ & $25(51.02 \%)$ \\
BMI, $\mathrm{kg} / \mathrm{m}^{2}$ & $24.8 \pm 3.7$ \\
Diabetes mellitus, $\mathrm{n}(\%)$ & $9(18.36 \%)$ \\
Hypertension, $\mathrm{n}(\%)$ & $21(42.85 \%)$ \\
CAD, $\mathrm{n}(\%)$ & $9(18.36 \%)$ \\
Smoking, $\mathrm{n}(\%)$ & $25(51.02 \%)$ \\
Duration of AF history, years & $4.04 \pm 2.52$ \\
LA diameter, mm & $41.77 \pm 4.49$ \\
LVEF $(\%)$ & $58.57 \pm 5.0 \mathrm{I}$ \\
CHA ${ }_{2} \mathrm{DS}$-VASc score, mean $\pm \mathrm{SD}$ & $1.36 \pm 1.20$ \\
EHRA score, mean \pm SD & $2.44 \pm 0.57$ \\
Follow-up time, months, mean $\pm \mathrm{SD}$ & $10.2 \pm 2.4$ \\
\hline
\end{tabular}

Note: $P<0.05$.

Abbreviations: $A F$, atrial fibrillation; $B M I$, body mass index; $C A D$, coronary artery disease; EHRA, European Heart Rhythm Association; LA, left atrium; LVEF, left ventricular ejection fraction; SD, standard deviation. 


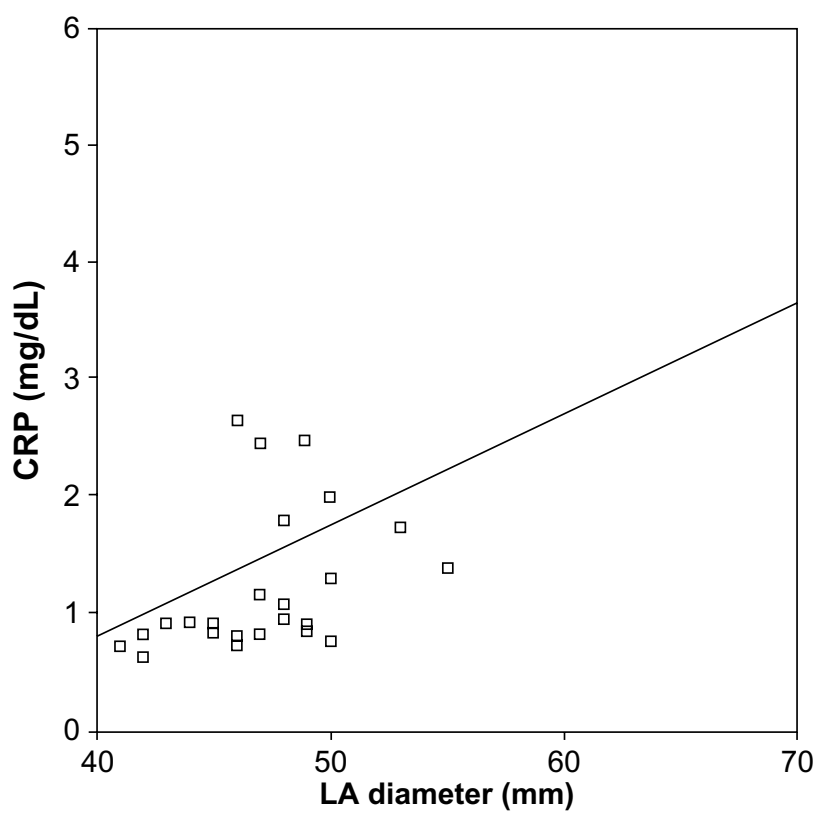

Figure I Correlation of plasma C-reactive protein (CRP) levels and left atrial (LA) diameter in the patients undergoing atrial fibrillation (AF) ablation procedure.

(64.59 \pm 15.39 vs 54.28 $\pm 11.32, P=0.033)$, had larger LA diameters (46.28 $\pm 4.30 \mathrm{~mm}$ vs $41.02 \pm 4.10 \mathrm{~mm}, P=0.002)$, and had a longer history of AF (6.71 \pm 4.57 years vs $3.79 \pm 1.72$ years, $P=0.003$ ) than patients with no recurrence (Group 2). The other baseline demographics were comparable between groups (Table 3 ).

Table 3 Baseline and procedural characteristics of patients with and without recurrence of $\mathrm{AF}$

\begin{tabular}{|c|c|c|c|}
\hline & $\begin{array}{l}\text { Group 2, } \\
(n=42)\end{array}$ & $\begin{array}{l}\text { Group I, } \\
(n=7)\end{array}$ & $\boldsymbol{P}$ \\
\hline $\begin{array}{l}\text { Unsuccessful AAD number } \\
(\text { mean } \pm \text { SD) }\end{array}$ & $1.4 I \pm 0.6$ & $1.40 \pm 0.7$ & 0.86 \\
\hline Age, years (mean $\pm S D)$ & $54.29 \pm 11.32$ & $65.01 \pm 15.39$ & 0.03 \\
\hline Sex, female; n (\%) & $22(52 \%)$ & $3(43 \%)$ & 0.65 \\
\hline $\mathrm{BMI}, \mathrm{kg} / \mathrm{m}^{2}$ & $24.8 \pm 3.6$ & $24.7 \pm 3.7$ & 0.12 \\
\hline Diabetes mellitus, $\mathrm{n}(\%)$ & $8(19 \%)$ & I (I4\%) & 0.19 \\
\hline Hypertension, n (\%) & $17(40 \%)$ & $4(57 \%)$ & 0.45 \\
\hline CAD, n (\%) & $8(19 \%)$ & I (14\%) & 0.45 \\
\hline Smoking, n (\%) & $22(52 \%)$ & $3(42 \%)$ & 0.655 \\
\hline Duration of AF history, years & $3.59 \pm 1.72$ & $6.7 I \pm 4.57$ & 0.003 \\
\hline LA diameter, mm & $41.02 \pm 4.10$ & $46.28 \pm 4.30$ & 0.002 \\
\hline LVEF (\%) & $58.92 \pm 4.88$ & $56.42 \pm 5.56$ & 0.14 \\
\hline $\mathrm{CHA}_{2} \mathrm{DS}_{2}-\mathrm{VASc}$ score, mean $\pm \mathrm{SD}$ & $1.30 \pm 1.13$ & $1.71 \pm 1.60$ & 0.41 \\
\hline EHRA score, mean \pm SD & $2.42 \pm 0.54$ & $2.57 \pm 0.78$ & 0.55 \\
\hline Mean minimal temperature $\left({ }^{\circ} \mathrm{C}\right)$ & $-49.02 \pm 3.19$ & $-47.28 \pm 2.30$ & 0.051 \\
\hline Mean occlusion grade & $3.90 \pm 0.17$ & $3.80 \pm 0.13$ & 0.55 \\
\hline Mean freezing time (minute) & $35.07 \pm 3.87$ & $36.85 \pm 4.74$ & 0.27 \\
\hline Mean application number & $9.14 \pm 1.38$ & $9.71 \pm 1.70$ & 0.33 \\
\hline
\end{tabular}

Note: $P<0.05$.

Abbreviations: $A A D$, antiarrhythmic drug; AF, atrial fibrillation; $B M I$, body mass index; CAD, coronary artery disease; EHRA, European Heart Rhythm Association; LA, left atrium; LVEF, left ventricular ejection fraction; SD, standard deviation.

\section{Procedure characteristics}

All patients were in sinus rhythm at the beginning of the procedure. The procedural endpoint of PVI was reached in all patients. A left-sided common ostium was seen in one patient. Three patients were in AF at the end of cryoablation. Sinus rhythm was achieved in all four patients after complex fractionated electrograms (CFE) ablation by radiofrequency catheter. At the end of CFE ablation, repeat induction was attempted in all four of these patients. Neither AF nor atrial tachyarrhythmia was induced after CFE ablation in any of these patients.

Mean procedure time and mean energy delivery duration were comparable for the groups. Although the difference was not statistically significant, mean minimal temperature was slightly higher in Group 1 than in Group 2 $(-47.28 \pm 2.30 \mathrm{vs}-49.02 \pm 3.19, P=0.051)$. Mean preprocedural activated clotting time levels and mean activated clotting time level during the procedure were comparable between the groups. Complications related to CA procedures included a major hematoma in the groin in one patient, a transient phrenic nerve paralysis in four patients, a gastroparesis in four patients, and a transient ischemic attack, which had resolved the day after, in another patient. There was no correlation between postprocedural high sensitive troponin values and the number of transseptal punctures or inserted femoral sheaths.

\section{Blood samples}

All hematological indices including both ESR and CRP were in the normal range. Both CRP and ESR were in the normal range before the procedure and both the values increased after the procedure (Table 4). The plasma levels of CRP were found to correlate significantly with LA diameter $($ rho $=0.517 ; P=0.009)$ (Figure 1).

\section{Predictors of AF recurrence after ablation}

The mean NLR values before and after catheter ablation were $1.92 \pm 0.68$ and $9.18 \pm 7.56, P<0.001$, respectively. There was no significant difference in the pre- or postablation NLR, CRP, or ESR between the two groups. Patients with AF recurrence had higher baseline RDW levels $(16.10 \% \pm 1.44 \%$ vs $14.87 \% \pm 0.48 \%, P<0.033)$.

Higher RDW level, longer history of AF, increasing age, and higher LA diameter are associated with increasing AF recurrence in univariate analysis. After multiple regression analysis including duration of $\mathrm{AF}$, age, LA diameter, and RDW blood level as covariates, only LA 
Table 4 Hematological indices of patients with and without recurrence of AF

\begin{tabular}{|c|c|c|c|c|}
\hline \multirow[t]{2}{*}{ Parameters } & \multicolumn{2}{|l|}{ Group 2} & \multicolumn{2}{|l|}{ Group I } \\
\hline & Preablation & Postablation & Preablation & Postablation \\
\hline Hemoglobin & $13.72 \pm 1.17$ & $|2.65 \pm| .3 \mid$ & $13.32 \pm 1.34$ & $13.32 \pm 1.49$ \\
\hline Neutrophil & $57.02 \pm 6.44$ & $78.7 I \pm 10.58 *$ & $61.40 \pm 5.56$ & $78.80 \pm 10.12 *$ \\
\hline Lymphocyte & $33.17 \pm 6.33$ & $13.72 \pm 8.38 *$ & $26.12 \pm 6.06 \pi$ & $14.42 \pm 6.45^{*}$ \\
\hline Monocyte & $7.14 \pm 2.01$ & $5.91 \pm 2.6 I^{*}$ & $8.78 \pm 1.38 \pi$ & $5.95 \pm 3.09 *$ \\
\hline Eosinophil & $1.85 \pm 1.45$ & $0.46 \pm 1.18^{*}$ & $2.57 \pm|.7|$ & $0.42 \pm 0.77 *$ \\
\hline Basophil & $0.74 \pm 0.31$ & $0.40 \pm 0.31$ & $0.90 \pm 0.10$ & $0.32 \pm 0.34$ \\
\hline MPV & $8.72 \pm 1.88$ & $8.54 \pm 1.15$ & $8.8 I \pm 1.40$ & $8.7 \mathrm{I} \pm 1.34$ \\
\hline WBC & $7.38 \pm 1.70$ & $10.40 \pm 3.39 *$ & $6.97 \pm 1.60$ & $9.87 \pm 3.43 *$ \\
\hline RDW & $\mid 4.87 \pm 0.48$ & $15.04 \pm 0.67$ & $16.10 \pm 1.44 \pi$ & $|6.28 \pm 2.4|$ \\
\hline CRP & $2.17 \pm 0.80$ & $14.09 \pm 6.75 *$ & $2.65 \pm 1.24$ & $16.32 \pm 7.24 *$ \\
\hline NLR & $1.83 \pm 0.63$ & $9.50 \pm 7.82 *$ & $2.50 \pm 0.78 \pi$ & $7.21 \pm 4.84^{*}$ \\
\hline
\end{tabular}

Notes: *Comparison of pre- and postablation values, $P<0.05$; "comparison of preablation values, $P<0.05$.

Abbreviations: AF, atrial fibrillation; CRP, C-reactive protein; MPV, mean platelet volume; NLR, neutrophil/lymphocyte ratio; RDW, red cell distribution width; WBC, white blood cell count.

diameter remained a significant predictor for ablation recurrence.

\section{Discussion}

Our study results demonstrated that an elevated baseline RDW level, and not CRP, NLR, or ESR, is independently associated with increased $\mathrm{AF}$ recurrence in the patients with paroxysmal AF after cryoablation. Increased LA diameter, longer history of $\mathrm{AF}$, and higher age were the other indicators of higher risk of AF recurrences. To the best of our knowledge, this is the first study investigating the role of all these hematological indices to predict AF recurrence after CA.

$\mathrm{AF}$ is the most commonly encountered arrhythmia and is an important cause of cardiovascular morbidity. Electrical and structural remodeling is important in initiation and perpetuation of the arrhythmia. Inflammatory process is accepted as an important factor in the development of structural remodeling such as myocyte degeneration and interstitial fibrosis. ${ }^{25}$ However, some recent studies did not establish any association between inflammatory markers and nonvalvular AF, debating the causal link between inflammation and $\mathrm{AF}^{26,27}$

The level of RDW reflects variability in the size of circulating red blood cells and is mostly used in differential diagnosis of anemia. However, many studies showed the association of increased RDW levels with adverse cardiovascular events independent of other hematological indices. ${ }^{28,29}$ Perlstein et $\mathrm{al}^{28}$ reported higher risk of all-cause mortality even in subjects with RDW values within reference levels (11.8\%-14.8\%) after full multivariable adjustment. RDW measurements were also strongly correlated with hs-CRP levels, which also predicted higher risk of mortality. ${ }^{28-30}$
Some mechanisms have been proposed for the association between RDW levels and cardiovascular outcomes. Oxidative stress and chronic inflammation may reduce survival of erythrocytes leading to a more mixed population of erythrocyte volumes in circulation. ${ }^{31-33}$

Güngör et $\mathrm{a}^{5}$ demonstrated that elevated RDW level and hs-CRP measurements were correlated with the rate of AF paroxysms. Gurses et $\mathrm{al}^{6}$ firstly investigated the relationship between preablation RDW and outcome of cryoballoonbased AF ablation. Consistent with our study, they found that RDW is significantly associated with both early and late $\mathrm{AF}$ recurrence following cryoballoon-based PVI for AF. However, the other indices of inflammation, which consist of CRP, ESR, and NLR, were not evaluated in this study.

Also, the present study revealed that plasma levels of hs-CRP are correlated well with LA size. This finding was in broad agreement with the results of our previous study, which demonstrated a correlation between LA size and an increased prevalence of $\mathrm{AF}^{34}$ In spite of this correlation of LA size and plasma levels of hs-CRP, plasma level of hs-CRP was not a predictor of AF recurrence.

NLR is another indicator of the inflammatory status that combines both neutrophils and lymphocyte. Higher level of NLR indicated a higher degree of inflammatory status in AF patients. Several studies have suggested that high NLR is associated with the presence or recurrence of AF. Gibson et al ${ }^{8}$ demonstrated that both preoperative and postoperative NLR elevations were related to the development of postoperative AF. In a recently published study, Canpolat et $\mathrm{al}^{35}$ found that elevated pre-NLR was associated with increased AF recurrence after cryoballoon-based catheter ablation. However, our study showed that neither post-NLR nor pre-NLR were the 
independent predictor of AF recurrence. Taken together, these results highlight the possible role of inflammation in both the remodeling process of the LA and the pathogenesis of AF.

\section{Limitations}

There are several limitations to the study. First, the sample size of the study is relatively small. Second, we did not measure markers of specific oxidative stress and inflammation other than hs-CRP. Third, despite regular screening of patients during outpatient visits with ECG and 24-h Holter recording, all recurrent episodes of AF may not have been detected. Furthermore, the design of the study identifies only an association and not causality.

\section{Conclusion}

However, it is revealed that there may be a potential role of inflammatory indices to predict recurrence of AF after cryoballoon; the actual predictor is still shown as increased LA diameter and longer history of AF, which demonstrate LA remodeling. For these reasons, it is impossible to determine whether the LA enlargement is the cause or the result of both the development of AF and the elevated plasma levels of RDW. RDW may represent a predictor of outcome following cryoablation, as an inexpensive marker of inflammation in AF. Further studies are needed to establish its exact pathophysiologic and prognostic roles.

\section{Author contributions}

All authors contributed toward data analysis, drafting and critically revising the paper and agree to be accountable for all aspects of the work.

\section{Disclosure}

There are no current funding sources for this study. No individuals employed or contracted by the funders (other than the named authors) played any role in: study design, data collection and analysis, decision to publish, or preparation of the manuscript. The authors declare that they have no competing interest.

\section{References}

1. Wolf PA, Abbott RD, Kannel WB. Atrial fibrillation as an independent risk factor for stroke: the Framingham Study. Stroke. 1991;22:983-988.

2. Miyasaka Y, Barnes ME, Gersh BJ, et al. Secular trends in incidence of atrial fibrillation in Olmsted County, Minnesota, 1980 to 2000, and implications on the projections for future prevalence. Circulation. 2006;114:119-125

3. Calkins H, Kuck KH, Cappato R, et al. 2012 HRS/EHRA/ECAS expert consensus statement on catheter and surgical ablation of atrial fibrillation: recommendations for patient selection, procedural techniques, patient management and follow-up, definitions, endpoints, and research trial design. Europace. 2012;14:528-606.
4. Tonelli M, Sacks F, Arnold M, Moye L, Davis B, Pfeffer M. Relation between red blood cell distribution width and cardiovascular event rate in people with coronary disease. Circulation. 2008;117:163-168.

5. Güngör B, Özcan KS, Erdinler İ, et al. Elevated levels of RDW is associated with non-valvular atrial fibrillation. JThromb Thrombolysis. 2014;37:404-410

6. Gurses KM, Yalcin MU, Kocyigit D, et al. Red blood cell distribution width predicts outcome of cryoballoon-based atrial fibrillation ablation. J Interv Card Electrophysiol. 2014;42:51-58.

7. Sawant AC, Adhikari P, Narra SR, Srivatsa SS, Mills PK. Neutrophil to lymphocyte ratio predicts short and long term mortality following revascularization therapy for ST elevation myocardial infarction. Cardiol J. 2014;21(5):500-508.

8. Gibson PH, Cuthbertson BH, Croal BL, et al. Usefulness of neutrophil/lymphocyte ratio as predictor of new-onset atrial fibrillation after coronary artery by pass grafting. Am J Cardiol. 2010;105: 186-191.

9. Arbel Y, Finkelstein A, Halkin A, et al. Neutrophil/lymphocyte ratio is related to the severity of coronary artery disease and clinical outcome in patients undergoing angiography. Atherosclerosis. 2012;225: 456-460.

10. Park JJ, Jang HJ, Oh IY, et al. Prognostic value of neutrophil to lymphocyte ratio in patients presenting with ST-elevation myocardial infarction undergoing primary percutaneous coronary intervention. Am J Cardiol. 2013;111:636-642.

11. Guo X, Zhang S, Yan X, et al. Postablation neutrophil/lymphocyte ratio correlates with arrhythmia recurrence after catheter ablation of lone atrial fibrillation. Chin Med J (Engl). 2014;127:1033-1038.

12. Celebi OO, Celebi S, Canbay A, Ergun G, Aydogdu S, Diker E. The effect of sinus rhythm restoration on high-sensitivity $\mathrm{C}$-reactive protein levels and their association with long-term atrial fibrillation recurrence after electrical cardioversion. Cardiology. 2011;118:168-174.

13. Barassi A, Pezzilli R, Morselli-Labate AM, et al. Serum amyloid a and C-reactive protein independently predict the recurrences of atrial fibrillation after cardioversion in patients with preserved left ventricular function. Can J Cardiol. 2012;28:537-541.

14. Hatzinikolaou-Kotsakou E, Tziakas D, Hotidis A, et al. Relation of $\mathrm{C}$-reactive protein to the first onset and the recurrence rate in lone atrial fibrillation. Am J Cardiol. 2006;97:659-661.

15. Henningsen KM, Therkelsen SK, Bruunsgaard H, Krabbe KS, Pedersen BK, Svendsen JH. Prognostic impact of hs-CRP and IL-6 in patients with persistent atrial fibrillation treated with electrical cardioversion. Scand J Clin Lab Invest. 2009;69:425-432.

16. Liu J, Fang PH, Dibs S, Hou Y, Li XF, Zhang S. High-sensitivity $\mathrm{C}$-reactive protein as a predictor of atrial fibrillation recurrence after primary circumferential pulmonary vein isolation. Pacing Clin Electrophysiol. 2011;34:398-406.

17. Lombardi F, Tundo F, Belletti S, Mantero A, Melzi D’eril GV. $\mathrm{C}$-reactive protein but not atrial dysfunction predicts recurrences of atrial fibrillation after cardioversion in patients with preserved left ventricular function. J Cardiovasc Med (Hagerstown). 2008;9:581-588.

18. Loricchio ML, Cianfrocca C, Pasceri V, et al. Relation of C-reactive protein to long-term risk of recurrence of atrial fibrillation after electrical cardioversion. Am J Cardiol. 2007;99:1421-1424.

19. Wazni O, Martin DO, Marrouche NF, et al. C reactive protein concentration and recurrence of atrial fibrillation after electrical cardioversion. Heart. 2005;91:1303-1305.

20. Rizos I, Rigopoulos AG, Kalogeropoulos AS, et al. Hypertension and paroxysmal atrial fibrillation: a novel predictive role of high sensitivity $\mathrm{C}$-reactive protein in cardioversion and long-term recurrence. J Hum Hypertens. 2010;24:447-457.

21. Watanabe E, Arakawa T, Uchiyama T, Kodama I, Hishida H. High-sensitivity C-reactive protein is predictive of successful cardioversion for atrial fibrillation and maintenance of sinus rhythm after conversion. Int J Cardiol. 2006;108:346-353.

22. Zarauza J, Rodríguez Lera MJ, Fariñas Alvarez C, et al. Relationship between C-reactive protein level and early recurrence of atrial fibrillation after electrical cardioversion. Rev Esp Cardiol. 2006;59:125-129. 
23. Camm AJ, Kirchhof P, Lip GY, et al; ESC Committee for Practice Guidelines. Guidelines for the management of atrial fibrillation: the Task Force for the management of atrial fibrillation of the European Society of Cardiology (ESC). Europace. 2010;12:1360-1420.

24. Packer DL, Kowal RC, Wheelan KR, et al; STOP AF Cryoablation Investigators. Cryoballoon ablation of pulmonary veins for paroxysmal atrial fibrillation: first results of the North American Arctic Front (STOP AF) pivotal trial. J Am Coll Cardiol. 2013;61:1713-1723.

25. Frustaci A, Caldarulo M, Buffon A, Bellocci F, Fenici R, Melina D. Cardiac biopsy in patients with "primary" atrial fibrillation. Histologic evidence of occult myocardial diseases. Chest. 1991;100: 303-306

26. Ellinor PT, Low A, Patton KK, Shea MA, MacRae CA. C-Reactive protein in lone atrial fibrillation. Am J Cardiol. 2006;97(9):1346-1350.

27. Schnabel RB, Larson MG, Yamamoto JF, et al. Relation of multiple inflammatory biomarkers to incident atrial fibrillation. Am J Cardiol. 2009;104(1):92-96.

28. Perlstein TS, Weuve J, Pfeffer MA, Beckman JA. Red blood cell distribution width and mortality risk in a community based prospective cohort. Arch Intern Med. 2009;169:588-594.
29. Patel KV, Semba RD, Ferrucci L, et al. Red cell distribution width and mortality in older adults: a meta-analysis. J Gerontol A Biol Sci Med Sci. 2010;65(3):258-265.

30. Lappé JM, Horne BD, Shah SH, et al. Red cell distribution width, $\mathrm{C}$-reactive protein, the complete blood count, and mortality in patients with coronary disease and a normal comparison population. Clin Chim Acta. 2011;412(23-24):2094-2099.

31. Kiefer CR, Snyder LM. Oxidation and erythrocyte senescence. Curr Opin Hematol. 2000;7:113-116.

32. Weiss G, Goodnough LT. Anemia of chronic disease. $N$ Engl J Med. 2005;352:1011-1023.

33. Grant BJ, Kudalkar DP, Muti P, et al. Relation between lung function and $\mathrm{RBC}$ distribution width in a population-based study. Chest. 2003;124:494-500.

34. Selcuk MT, Selcuk H, Maden O, et al. Relationship between inflammation and atrial fibrillation in patients with isolated rheumatic mitral stenosis. J Heart Valve Dis. 2007;16:468-474.

35. Canpolat U, Aytemir K, Yorgun H, et al. Role of preablation neutrophil/ lymphocyte ratio on outcomes of cryoballoon-based atrial fibrillation ablation. Am J Cardiol. 2013;112:513-519.
Journal of Blood Medicine

\section{Publish your work in this journal}

The Journal of Blood Medicine is an international, peer-reviewed, open access, online journal publishing laboratory, experimental and clinical aspects of all topics pertaining to blood based medicine including but not limited to: Transfusion Medicine; Blood collection, Donor issues, Transmittable diseases, and Blood banking logistics; Immunohematology; Artificial and alternative

\section{Dovepress}

blood based therapeutics; Hematology; Biotechnology/nanotechnology of blood related medicine; Legal aspects of blood medicine; Historical perspectives. The manuscript management system is completely online and includes a very quick and fair peer-review system. Visit http://www.dovepress.com/ testimonials.php to read real quotes from published authors.

Submit your manuscript here: http://www.dovepress.com/Journal-of-blood-medicine-journal 